\title{
Factors Influencing HIV/AIDS and Risky Sexual BehaviourAmong Learners in South Africa
}

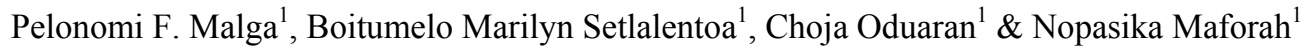 \\ ${ }^{1}$ Social Work, North-West University, South Africa \\ Correspondence: Pelonomi F. Malga, Social Work, North-West University, South Africa.
}

Received: January 27, 2018 Accepted: February 20, 2018 Online Published: April 30, 2018

doi:10.5539/gjhs.v10n5p197ＵRL: https://doi.org/10.5539/gjhs.v10n5p197

\begin{abstract}
HIV/AIDS is a global health concern and young people are more at risk of being infected. The explored factors that contribute to HIV/AIDS and risky sexual behaviour among learners aged 12-18 years in Vuyolwethu High School. The study focused on learners who were in Grade 10-12. This study employed a mixed method research. Quantitative phase was limited to learners while the qualitative phase focused on life-orientation teachers. The total study sample is 150 , and the gender distribution is equally distributed at $50 \%$ for both males and females. The dominating age and grade among respondents is age 17-18 years and grade 11. Quantitative data were subjected to descriptive analyses while thematic analysis is employed for analysis of qualitative data. Overall, about $51.3 \%$ of the respondents strongly agreed that engaging in sexual intercourse without protection is risky, and that unprotected sexual activity can lead to unwanted sexual encounters, unwanted teenage pregnancy and HIV/AIDS. Similarly, substance abuse is found to be a key factor that influences risky sexual behaviour among adolescents, thus resulting to unwanted pregnancies and HIV/AIDS infection. The main conclusion drawn from the findings is that while adolescents seem to be knowledgeable on the factors that contribute to risky sexual behaviour, this knowledge does not lead to attitude change. It is therefore recommended, based on the study's findings, that there should be more focused training programmes directed not only at knowledge but also attitude and behaviour change.
\end{abstract}

Keywords: poverty, substance abuse, risky sexual behaviour, factors \& HIV/AIDS

\section{Introduction}

Today's youth are the largest in history with nearly half of the global population being younger than 25 years of age (UNAIDS, 2004:93). How the youth behave will determine the future of the HIV/AIDS pandemic. These behaviours will depend largely on their knowledge what they know, their perceptions and their attitudes regarding HIV/AIDS (Tarkang, Van der Wal, \& Ehlers, 2011). HIV and AIDS is a more noticeable sexually transmitted disease, which causes illness and deaths among mature adults. The group at greater risk are those between 15 and 50 years of age, who are often considered as the most sexual active group (Barnett \& Whiteside, 2002). This put emphasis on the group at risk of contracting HIV and AIDS, hence it is said to be a sexually transmitted disease as many contract it through sexual contact.

In both developed and developing countries, the increasing incidence and prevalence of sexually transmitted infections including HIV among adolescents and youth give a serious challenge in their health and well-being (Molefe, 2013:1). Molefe (2013) argues that developing countries, such as South Africa, have the high risk of sexual behaviour that young people involve themselves in. Economically, young people engage in unprotected or unsafe sex in exchange of money, hence spreading of numerous diseases, that government need to intervene in implementing Anti-Retroviral sites in hospitals. Molefe (2013) explains further that parents find it not easy to discuss or communicate with their adolescents about sexual matters, which increases the high chances of young adolescents having little information about how to protect themselves from getting STIs, thus exposing them to risky sexual behaviours.

Adolescents' risky sexual behaviour is an issue that everyone needs to be concerned with as it affects the lives of all individuals, parents, educators as well as the national and provincial governments. Consequently, the health and economic sector/ department are influenced negatively. Given the risks of unprotected sexual activity during adolescence, which result in a high prevalence of teenage pregnancy and other sexually transmitted diseases that may lead to the infection of HIV/AIDS, young people are considered sexually active. Therefore, this study 
targets learners with the age group of 12-18 in a High School.

\section{Statement of the Problem}

HIV/AIDS is regarded as not only a medical problem but also a public health problem. Sub-Saharan Africa constituted $10 \%$ of the total population in the world; it disproportionately accounted for $85 \%$ of the world's AIDS deaths (Klomegah, 2011). South Africa is one of the countries that has large numbers of HIV statistics in Africa and in the world increasing the deaths of people and children more-than all deceases. HIV/AIDS brings negative impact to the country's wealth and economy (Amuzu, 2007).

UNAIDS reported that women are at a greater risk of contracting HIV through unprotected vaginal intercourse compared to men. The reason for this is that: 'women possesses a wider surface area of mucosa in the thin lining of the vagina and cervix than men'. Semen infected with HIV typically contains higher concentration of virus than a woman's sexual secretions. This makes male-to-female transmission more efficient than female-to-male' (UNAIDS, 1997).

Marais (2005) argued that there are researches stating that there is a connection between sexual and other types or forms of abuse against women which increases the chances of them getting infected by HIV/AIDS. Violence between intimate partners has been linked to increased chance of HIV infection somehow come out to be solid. Cameroon \& Richter (2008) argue that HIV/AIDS has dramatically made human security in South Africa to be at a great disadvantage. It has made living conditions to be difficult for the vulnerable and the poor. On the other side, the stigma attached to this infection makes these conditions to be worse. The provisions of ARVs through public healthcare system are essential for the successful management of the HIV/AIDS epidemic in South Africa Access to equal healthcare, treatment and prevention are vital components, not only for the individuals' human security but for also the security of the future of the nation as a whole.

HIV/AIDS has been categorised as a worldwide public health challenge as young people are the mostly infected and affected by the virus. This raises up issues of many STI's associated to this disease despite several preventive strategies that have been established. Young people show reluctance to the using of those preventive measures which include usage of condoms during sexual intercourse, regular testing, hence they sometimes have relationships with another partners whom may infect them. The high prevalence of HIV/AIDS among young people will increase as years to come by (Zastrow \& Kirst-Ashman, 2013). In view of the problem statement, the following are the study's objectives.

\subsection{Objectives of the Study}

The specific objectives of this study are:

1) To determine the recurring reasons why learners engage in risky sexual behaviours such as unprotected sex

2) To identify educators' views regarding factors that increase the HIV/AIDS prevalence as well as unprotected sex among students.

3) To provide ways on how to encourage safe sex among learners.

\subsection{Research Questions}

1) What are the recurring reasons why learners engage in risky sexual behaviours such as unprotected sex?

2) What are the predominant educators' views regarding factors that increase the HIV/AIDS prevalence as well as unprotected sex at the school?

3) What are the possible ways on how to encourage safe sex among learners?

\subsection{HIV/AIDS and Risky Sexual Behaviours}

Young people are the future of a nation, yet it is the generation that is most vulnerable and at risk of getting infected by HIV which causes AIDS (Centers for Disease Control and Prevention, CDCP, 2010). Zastrow and Kirst-Ashman (2013:443) posit that a "virus is a protein-coated package of genes that invades a healthy body cell and alters the normal genetic apparatus of the cell, causing the cell to reproduce the virus". This virus weakens the body's immunity against infections; for instance, the disease affects a person's immune system and allows other diseases such as sexually transmitted infections to gradually make an individual's body not function very well.

HIV/AIDS has been described as a sexually transmitted disease which causes illness and ultimately deaths in young people who are between the ages of 14 and 25 as they are often considered as the 'sexual active'. HIV disease is "characterised by a gradual deterioration of immune function, most notably crucial immune cells 
called CD4 and T cells are disabled and killed during the typical course of infection. These cells sometimes called 'T-helper cells' play a central role in the immune response, signalling other cells in the immune system to perform their special functions. During HIV infection the number of these cells in a person's blood progressively decline and when a person's CD4 cell count falls below 200 he or she becomes particularly vulnerable to the opportunistic infections and cancers that typify AIDS, the end stage of HIV disease. People with AIDS often suffer infections of the intestinal tract, lungs, brain, eyes, and other organs, as well as debilitating weight loss, diarrhoea, and neurologic conditions" (Bellenir, 1999:17-18).

Risky sexual behaviour referred to such a behaviour that increases an individual chance of contracting sexually transmitted infections as well as unplanned pregnancies. It includes engaging in sexual activities at an early stage, having multiple partners, and sex under influence of alcohol/drugs and unprotected sexual behaviour (CDCP, 2010).

Adolescents tend to experiment with risky behaviours including sexual intercourse. Sexual intercourse practised not using condoms which is considered unsafe sex and may result in sexually transmitted diseases as well as HIV Infection. Cigarette smoking behaviour is mostly dominated by boys and may lead to consumption of using other substances like glue, while alcohol consumption also plays a role in the occurrence of risky sexual behaviour which mostly adolescents turn to for an experiment, thus resulting in contracting HIV/AIDS when an individual has multiple partners.

\subsection{HIV/AIDS in South Africa}

According to Barnette and Whiteside (2000:13), HIV/AIDS has changed the lives of individuals, ruined their health, and caused their deaths while leaving survivors to mourn. It is changing not only the individual lives but also the trajectories of the whole society. AIDS was first diagnosed in South Africa among two patients in the year 1983. In the same year, death was recorded owing to AIDS. It increased to 46 cases in 1986, estimated from 2000 which indicated that $5 \%$ of actual infections and only $1 \%$ of actual deaths due to AIDS were reported prior to 1990 . Prior to 1990, AIDS was more common among men who had sex with men. By 1990, less than $1 \%$ of South Africans had AIDS. By 1996, the figure stood at around 3\% and by 1999 the figure had reached 10\%. The infection became pandemic and worrisome around 1995 (Barnett \& Whiteside, 2002). The impact of HIV on young people is different from its impact on other age groups or communities. The youth acquire HIV through heterosexual transmission as compared with adults; a higher percentage of youth patients are asymptomatic, becoming symptomatic with HIV-related illnesses during adulthood (Blair \& Hein, 1994).

Scholars such as Booysen (2002) believes that South Africa is one of the countries with worst cases of HIV/AIDS epidemic, and HIV in this country is transmitted through sexual intercourse. Furthermore, Okorie and Bigala (2016: 440) observed that "South Africa has the highest profile HIV epidemic compared to any country in the world...about 6.3 million people in South Africa live with HIV/AIDS in 2013. Furthermore, there were 396,000 new infections, while 200,000 South Africans died from AIDS-related diseases in 2013". However, awareness campaigns on protected sex remain central in the government's current policy toward HIV/AIDS and risky sexual behaviour among young people. Poverty contributes to risky sexual behaviour and HIV infection among people by increasing vulnerability of women to HIV infection and resulting in unsafe sex activities due to lack of knowledge, lack of access to means of protection and inability to negotiate use of condoms with their sexual partners as a result of entrenched gender roles and power relations.

In South Africa, sex is considered as a recreation, having many partners is acceptable especially to Swazi and Zulu people. Young women are in a disadvantaged position compared to men, while the female economic activity rate is $59 \%$ of the male. Male have more power than women when it comes to sexual activities because men are the one who coerced women into sexual intercourse. Poor young women are more likely to have nonregular sexual partners and that condom use with non-regular partners is significantly lower among poor women. Other works have shown that risky sexual behaviour to be associated with high socio-economic status.

Moreover, cultural norms and beliefs encourage men to have multiple partners in the sexual relation and blame women who do the same. Culture requires women to be slave to their husbands and also submit to men's authority which may sometimes lead them to HIV/AIDS because the men have the right to sleep with many different women as culture do not encourage men to use protection. For example, in Zulu culture, people believed that for men to protect themselves from HIV infection, they have to bath after sexual intercourse. This contributed to why at Kwa Zulu Natal province, there is high profile of HIV/AIDS. To add on that, HIV and risky sexual behaviour have been looked in different behaviours including not using condom during sexual intercourse, having many partners, and having sex with a person infected by HIV/AIDS disease. According to several studies that were conducted in South Africa, young people engage themselves in sexual contact at the 
early stage due to inadequate knowledge, low literacy level, as well as having low self-esteem. At the early stage, young people are scared to say no to their sex partners (Booysen, 2002). It is evident that HIV and risky sexual behaviour is increasing drastically in South Africa because people take sex as fun, especially young people. Government, non-governmental sector and youth organisations need to fight against this disease. It involves every individual to stand up and come up with alternatives strategies to address HIV/AIDS and risky sexual behaviour among young people.

\section{Method and Materials}

The type of research employed in the current study is a mixed methods approach. The study adopts both qualitative and quantitative research methods to explore and describe the factors contributing to HIV/AIDS and risky sexual behaviour among learners. This approach is selected because of its ability to provide an opportunity to gain full understanding of the research problem by utilising the two types of research approaches (quantitative and qualitative methods) in the same study.

The study uses one of the most popular mixed methods in educational research: sequential explanatory mixed methods design, consisting of two distinct phases (Creswell, 2003). In the first phase, the quantitative, numeric data was collected first, using a cross-sectional survey and the data is subjected to a positivism analysis .The goal of the quantitative phase is to identify variables influencing factors that contribute to HIV/AIDS among learners, thus allowing convenient selection of informants for the second phase.

The second phase involves qualitative data collection through interviews. This allowed the researcher provide explanation for exploring certain factors at the quantitative phase as well as their relevance to learner's views on the link between HIV/AIDS and risky sexual behaviour. The rationale for this approach is that the quantitative data and results provide a general picture of the research problem in terms factors that contribute to the high prevalence of HIV/AIDS among young people.

In this study, data was collected atVuyolwethu High School, a public secondary school located in Ipeleng, Galeshewe, SolPlaatjie Local Municipality, Northern Cape Province in Kimberley. Galeshewe is a township in Kimberley, South Africa, situated in the Sol Plaatje Local Municipality, Northern Cape Province, South Africa. It was named after Kgosi (Chief) Galeshewe. The motivation for the choice of setting is that the school has got a reputation for having learners who use substances which is capable of leading them to contract the disease. Areas in Galeshewe where most learners reside, are filled with taverns and drugs, which are easily accessible as well as affordable. Learners coming from such backgrounds can be easily influenced to partake in risky sexual behaviours.

The population of the study is adolescents in Vuyolwethu High School. The proposed study reached out to all individuals in the target or accessible population. In this case, all learners aged 12-18, are part of the sample frame. For quantitative phase, probability sampling is adopted, which made use of stratified random and clustering sampling. The stratified random sampling is divided in a form of homogenous with characteristics that include gender and age, clustering sample is employed in the study in a form of learners with different gender and age, in particular different grades in school. Non-probability was followed in the second phase, which includes the convenience sample. Teachers of life orientation were easily available at schools, hence the present study used life orientation educators as participants for the interview part.

\subsection{Ethical Considerations}

Research ethics are an overriding concern when it comes to the choice of strategy (Denscombe, 2010). Upfront permission for conducting research was obtained from the Department of Education and the North West University Ethics Committee. The ethical principles observed in the study are outlined below.

a. Confidentiality: Confidentiality is when the researchers assures participants that identifying information will not be made available to anyone who is not directly involved in the study (Nicholas, Rautenbach, \&Maistry, 2010:200) In this study everything possible, however was done to ensure that information obtained from the participant is treated as confidential, although sensitive information will remain between participant and researcher.

b. Do No Harm: Do no harm refers to the requirement that researchers may not put the participants in a situation where they might be in physical and or/ psychological danger as a result of their participation (Nicholas et al., 2010: 200).In the study, no harm was done to members participating, either physical or psychological.

c. Voluntary Participation: The researcher ensured that the participants are participating from their own 
free will and no one was forced to participate in the study. (Nicholas et al, 2010:200)

d. Informed Consent: Informed consent is a key in social research ethics. It implies that prospective research participants should be given as much as information as might be needed to make an informed decision about whether or not they wish to participate in a study (Bryman, 2012). In the current study, no information was obtained from a learner without their consent.

e. Anonymity: Anonymity is the protection of participant's identity and this can be clearly stated through utilising anonymity of the participants (Arkaah, 2014: 68). All learners participating in this study were not allowed to provide their identity hence they remained anonymous.

f. Role of the Researchers: The researchers' part in collecting data in the two phase of the study is different. The first phase of the study, quantitative phase, the researcher administered questionnaires/surveys to learners; the second phase of the study, qualitative phase, the researchers did the structuring of interviews and also conduct interviews with educators.

\section{Results}

The study was conducted in Vuyolwethu High school in the Retswelele area in Kimberley. The focus of this chapter is on the presentation, analysis and interpretation of the findings. This was a mixed method research study aimed at 'exploring the factors that contribute to HIV/AIDS and risky sexual behavior among adolescents' A cross-sectional survey was used to collect quantitative data, with a total of 150 respondents; and semistructured face-to-face interviews were scheduled to collect qualitative data from life orientation educators.

The study employed the sequential explanatory mixed method design which had two phases: the quantitative phase first followed by the qualitative phase. The data presentation and analysis will be categorized into these two phase. Data was presented in four sections. Section "A" specified the demographic information and background of learners. Section "B" examined the learner's perceptions about sex-related issues. Section "C" examined the usage of substances among adolescents; Section "D" related to the use of contraceptives and teenage pregnancy while the last section, Section E was directed at the knowledge learners have about HIV/AIDS. Data was analysed using SPSS; and the data presentation was done using frequency tables, graphs and figures. Where necessary, percentages were rounded to the next decimal number to add to 100 .

\section{Section A: Demographics}

\section{Study Population by Gender}

Questionnaires were administered to a probability sample of 150; and the actual study population reached after data capturing and cleaning was 150 . The achieved research sample size was $100 \%$. Interestingly enough, the sample constituted an equal distribution of males and females, $50 \%(\mathrm{~N}=75)$. It is important to state upfront that this was a coincidence as respondents were randomly selected. The gender study sample reflecting the gender distribution is graphically presented in Figure 1 below.

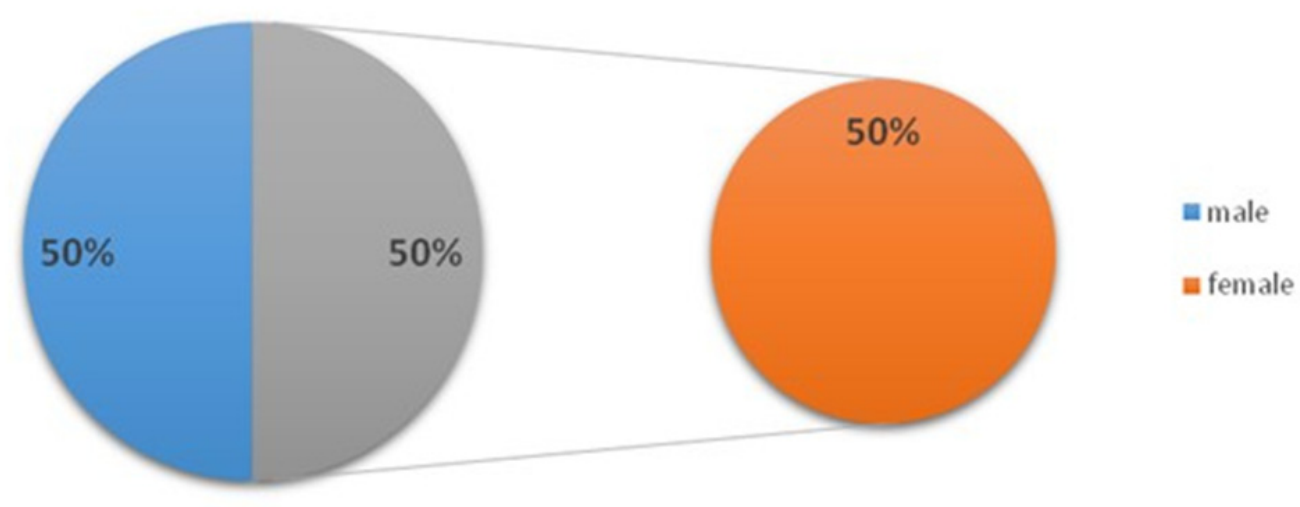

Figure 1. Gender Distribution 
As presented in Figure 2, majority of the respondents, 97 (64,6\%) were in the 17-18 age group followed by 1516 years with $37(24,7 \%)$ and lastly, $19-20$ age group with 16 participants, about $10,7 \%$.

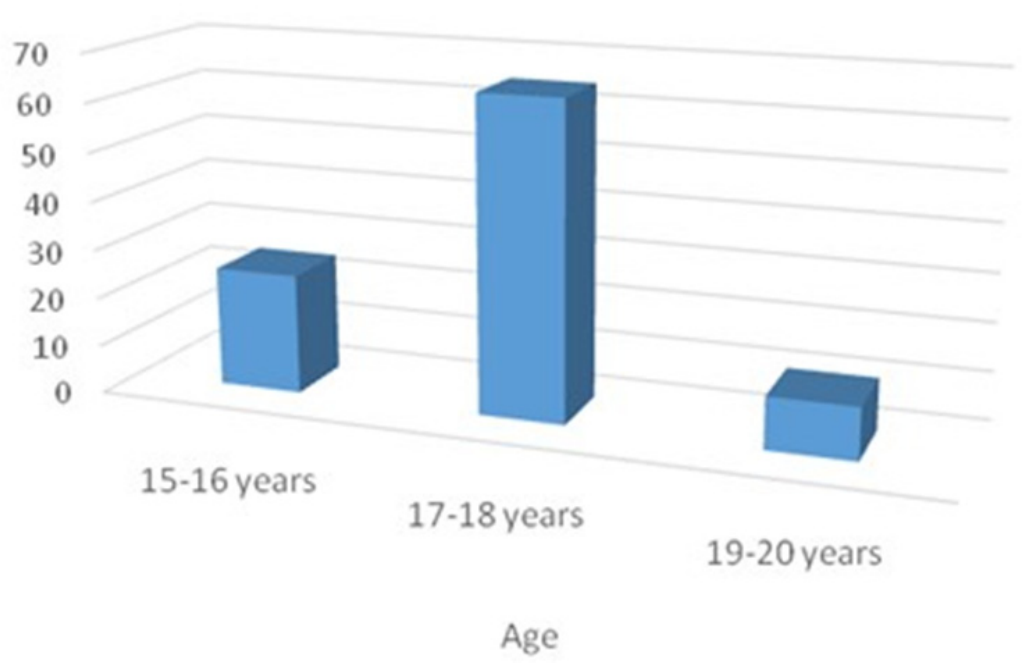

Figure 2. Age

\section{School Grade (Education Level)}

The Grade 11 represented the largest percentage of the sample, $42 \%(\mathrm{~N}=63)$ followed by Grade $10,36 \%(\mathrm{~N}$ $=54)$ and Grade $12,22 \%(\mathrm{~N}=33)$. The education level is illustrated graphically in Figure 3 below.

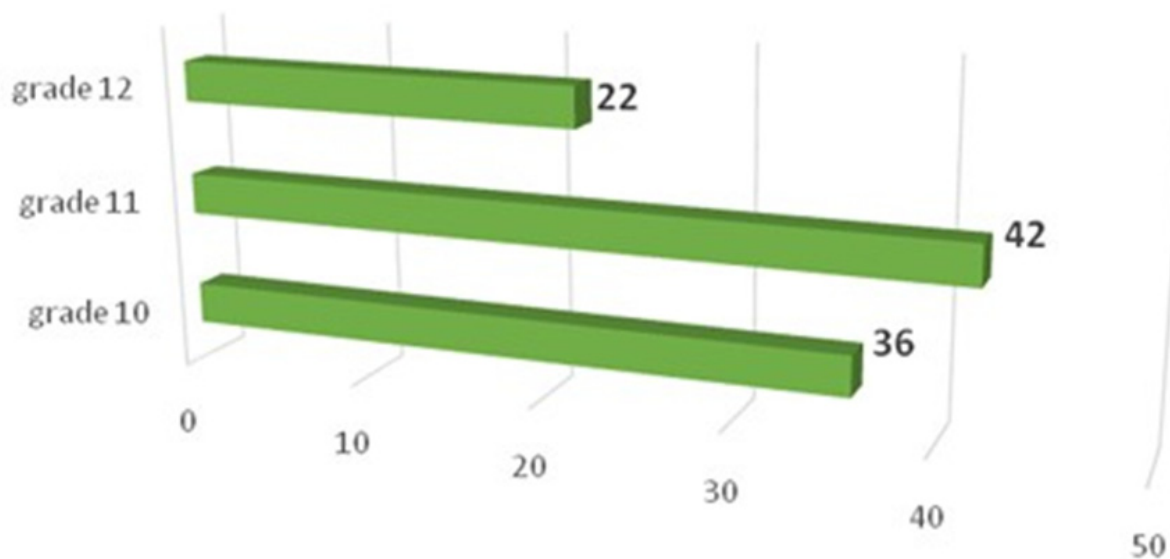

E Participation of learners from each grade

Figure 3. Sample Participation by School Grade

\section{Section B: Perception about Sex Related Issues}

Teenage learners can be exposed to a variety of perceptions, beliefs and attitudes to sex related issues. Perceptions about sex issues to adolescents can be crucial in determining factor of sexual activity or engagement. Learners have their own strong views on what perception and attitude they should hold and what principles should control them. This section examines the learners' perceptions about sex-related issues.

The findings on the learner's perceptions about sex related issues are presented below according to the following categories: condoms, unprotected sex, multiple partners and peers. 


\section{Unprotected Sex}

Figure 4 below indicates that a large number of respondents agreed that involvement in sexual relationship at an earlier age can lead to unprotected sexual encounters $n=80(54 \%)$, hence the issue of teenage pregnancy in schools because learners are involved in sexual relationships at an earlier age.

\section{Multiple Partners}

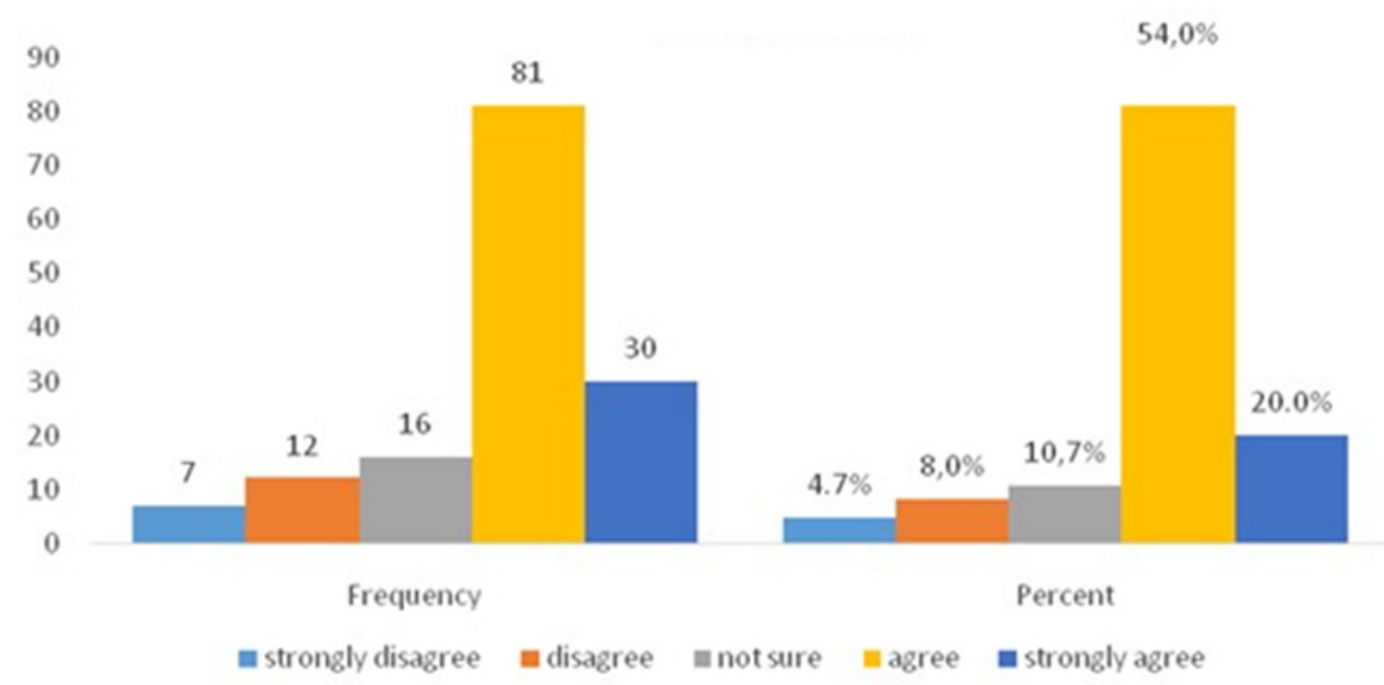

Figure 4. Unprotected Sex

When participants were asked if having multiple partners increases the chances of HIV/AIDS infection, Figure 5 indicates that an overwhelming majority $74 \%(\mathrm{n}=111)$ of respondents demonstrated that having multiple partners can increase the chances of HIV/AIDS infection whilst $12 \%(\mathrm{n}=18)$ respondents disagreed.

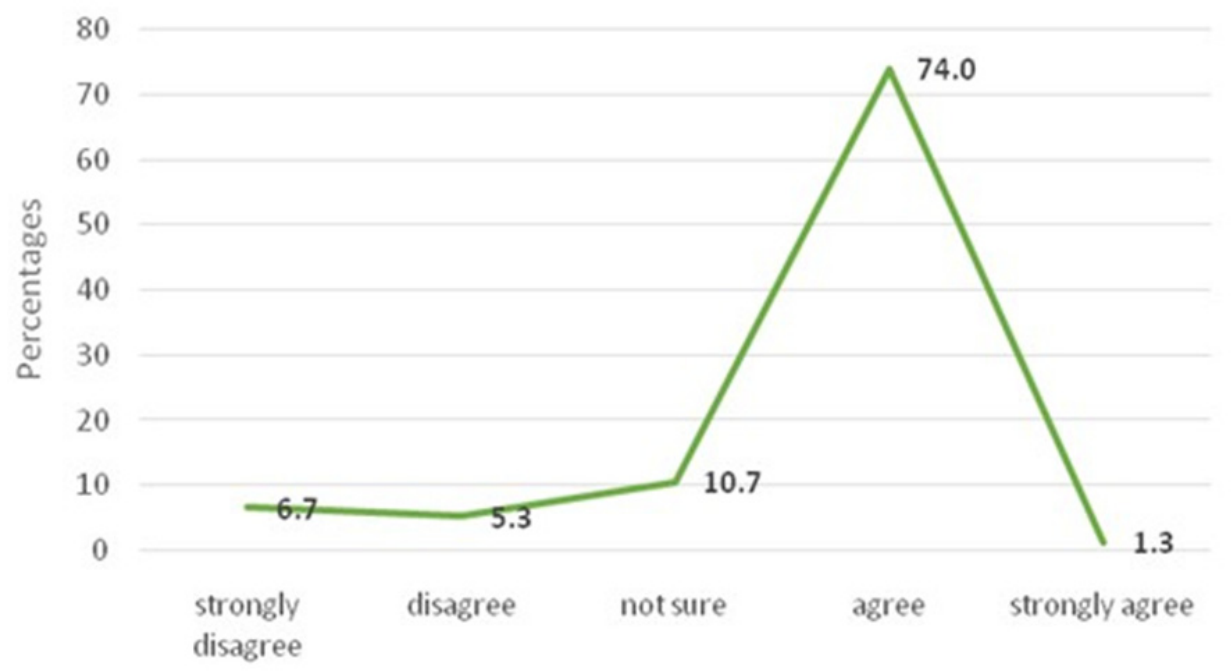

Figure 5. Multiple Partners

\section{Section C: Substance Abuse}

Section C was intended to assess participants' pattern of substance abuse as a rite of passage to adulthood, whilst substance use by younger people is often experimental (Nelson, 2012). The findings are presented below.

When participants were asked about the effect of alcohol and drugs leading to irresponsible behavior $56 \%$ of 
respondents demonstrated that alcohol and drugs have an effect on irresponsible behaviour, $28 \%$ respondents demonstrated that alcohol and drugs do not have an effect on irresponsible behaviour and $16 \%$ respondents were not sure if alcohol and drugs have an effect or not on irresponsible behavior (see Figure 6 below).

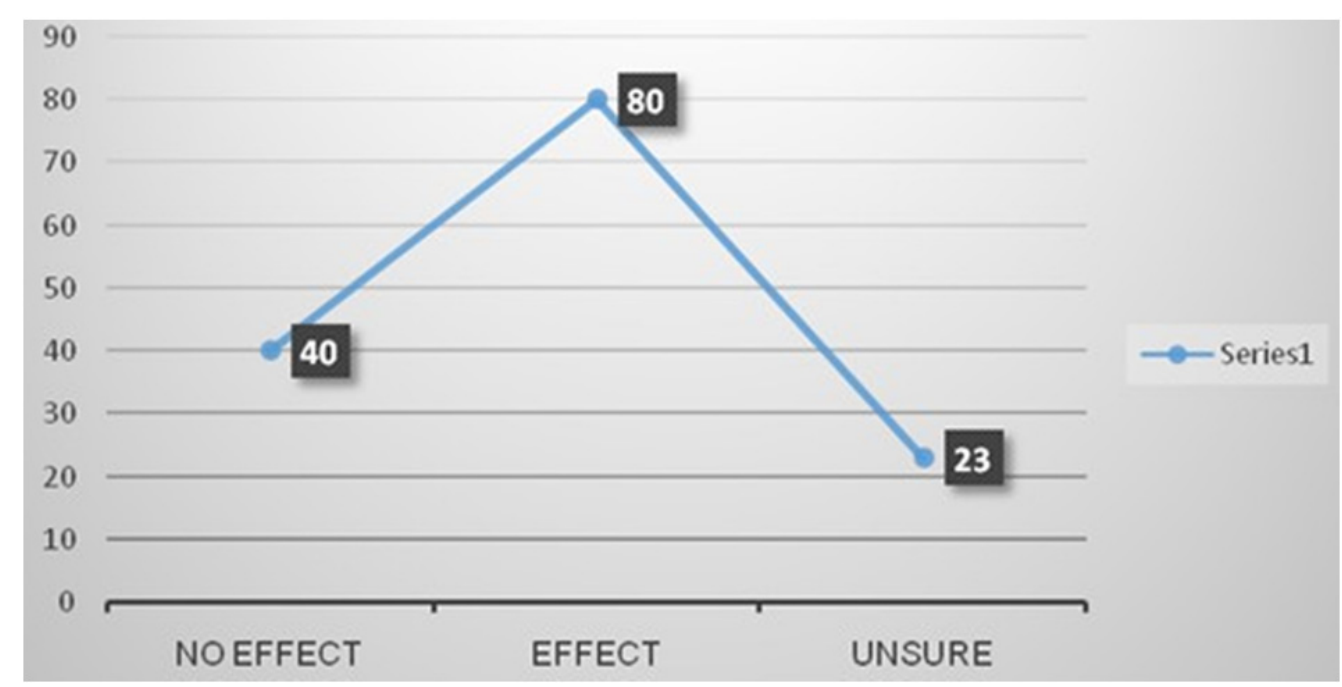

Figure 6 . The effect of alcohol and drugs leading to irresponsible behavior

\section{Section D: Teenage Pregnancy}

Teenage pregnancy is a social problem and a sensitive issue at schools. This section focused on contraceptives and how teenage pregnancy can be managed or controlled.

\section{Contraceptives}

A large percentage of respondents, $68.0 \%(n=102)$ indicated that contraceptives can lead to unprotected sexual behaviour as opposed to a smaller $27.3 \%(n=40)$ indicated that contraceptives do not lead to unprotected sexual behaviour. However, a significant number indicated that contraceptives can encourage the use of contraceptives as "it stops the egg from being fertilized". It seems as if "they are more afraid of being infected by HIV/AIDS than getting pregnant.

\section{Prevention of Teenage pregnancy}

To the question of 'how teenage pregnancy can be prevented?', Table 1 below indicates that majority of respondents, about 53\% $(\mathrm{n}=79)$ indicated 'encouraging protected sex'. Other positive responses such as 'providing more condoms in schools', 'encouraging contraceptives'; and 'providing HIV/AIDS training' also ranked fairly high, demonstrating a positive attitude towards prevention of risky sexual behaviour.

Table 1. Prevention of Teenage Pregnancy

\begin{tabular}{llll}
\hline Prevention ofTeenage Pregnancy & No.of Participants & $\%$ & Cumulative \% \\
\hline Providing more condoms in schools & 24 & 16.0 & 16.1 \\
Encouraging contraceptives & 27 & 18.0 & 34.2 \\
Having HIV/AIDS education & 18 & 12.1 & 46.3 \\
Encouraging protected sex & 79 & 52.7 & 99.3 \\
Missing & 1 & 7 & 100 \\
Total & 150 & 100 & 100 \\
\hline
\end{tabular}

\section{Section E: HIV/AIDS Education}

This section focused on the knowledge learners have about HIV. The findings on the learners' knowledge about HIV education are presented below according to the following categories: Polygamous marriages, sleeping with 
a Virgin, Peer Education, and Reduction of HIV.

\section{Polygamous Marriages}

To the question: "Are people in polygamous marriages cannot be infected with HIV/AIDS?" participants responded that "no" $(\mathrm{N}=127), 85 \%$, and others responded that "yes" $(\mathrm{N}=20), 13.3 \%$.

Virgin

To the question: "Is sleeping with a virgin cure HIV/AIDS", the majority of learners responded that it can not $127(85 \%)$ and other agreed that sleeping with a virgin can cure HIV/AIDS, 20(13.3\%).

\section{Peer Education}

Learners were asked if Peer education can reduce the spread of HIV/AIDS, majority of $88(61 \%)$ learners agreed that peer education can reduce HIV/AIDS and 57(39\%) of learners disagreed.

\section{Not Spreading Means}

To the question "how one can prevent the spread of HIV/AIDS", most learners indicated that they know about HIV/AIDS education, 120 respondents know what the causes of HIV/AIDS are, how one can prevent the spread of HIV/AIDS and that male circumcision is not a $100 \%$ preventive measure from getting infected by HIV/AIDS. One hundred and eighteen respondents knew preventive means of not spreading HIV/AIDS (see Figure 7 below).

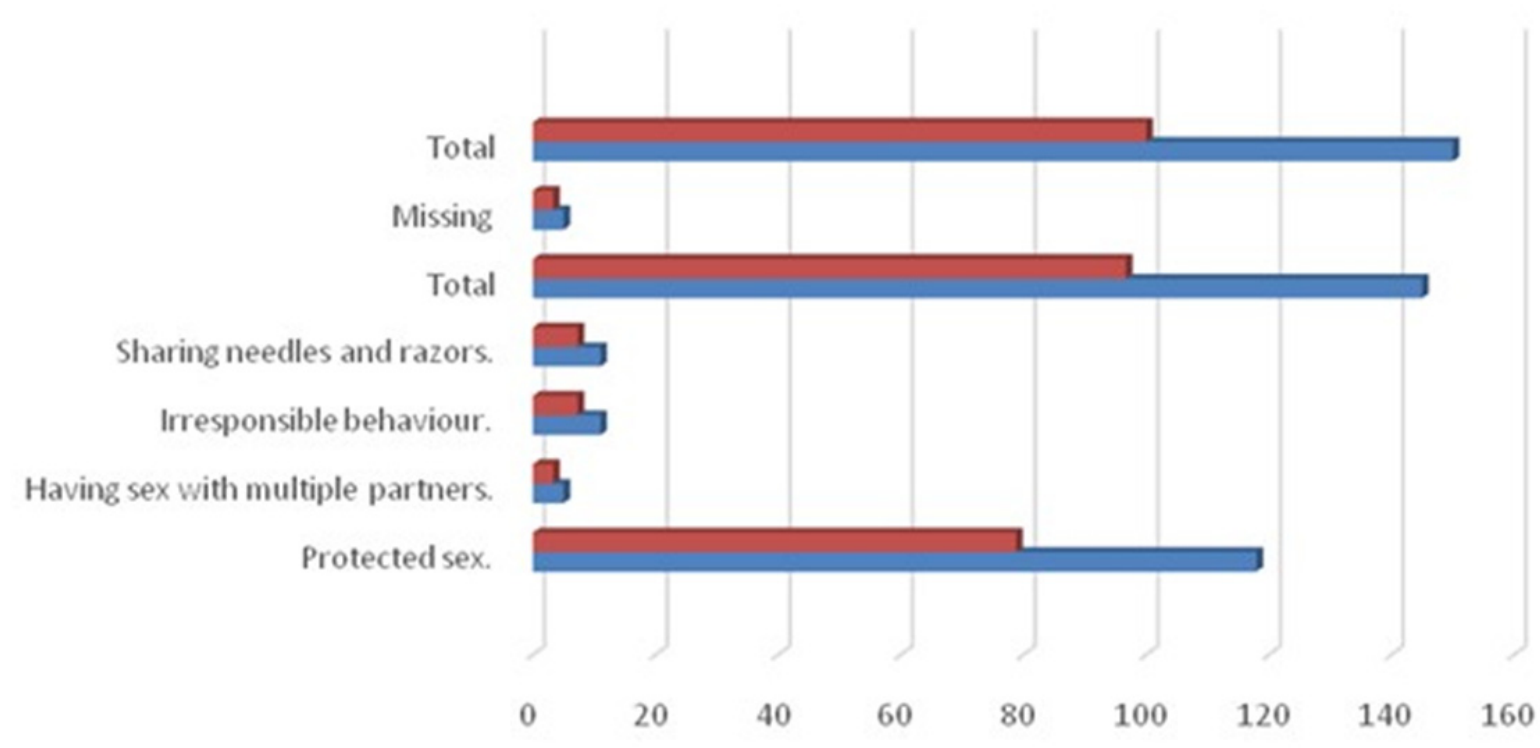

Figure 7. Not Spreading HIV/AIDS

Phase 2: Qualitative Data Analysis

This chapter focused on the analysis and presentation of data that was collected for the study. The data presentation and analysis was guided by the methodology described earlier on which also provided the baseline for data gathering. The presentation of data is systemically linked to the format of a semi-structured face-face interview. Creswell (2003:190) describes data analysis as the process of data analysis which involves making sense out of text or image data. It also involves preparing the data analysis, conducting different analyses, moving deeper and deeper into understanding the data, representing the data and making an interpretation of the larger meaning of the data. The findings present the responses by educators as participants.

The purpose of the study was to explore factors contributing to HIV/AIDS and risky sexual behaviour by interviewing life-orientation educators at Vuyolwethu High School to get deeper sense of the particular research topic. An interview schedule was prepared to get the educators' perceptions and understanding of the issues. The face-to-face interviews centered on the following key questions:

Reasons why learners engage in risky sexual behaviors such as unprotected sex;

This section covers a presentation of the research findings of the study with a view to formulating an answer to 
the main qualitative research question which is: What are the factors contributing to HIV/AIDS and risky sexual behavior among high school learners? Themes and sub-themes were formulated from the participants' voices and meanings; and these formed the basis for the thematic analysis process.

\section{Biographical Data of Educators}

Participants were purposely selected on the basis of being the Life Orientation Teachers at Vuyolwethu High school. Participants constituted four (4) teachers, all life orientation teachers, African and ranging between 36 and 50 years.

Presentation and Analysis of Data: From Codes to Themes

The analysis of data took the form of identifying thematic areas from coding them and reducing them to themes. The initial thematic analysis is outlined in Table 2 below followed by a further analytic process of reducing basic themes to organising themes and global themes in Table 3. This thematic process is consolidated through a discussion and ends with conclusions and recommendations.

Table 2. From Codes to Themes on Educators' Views factors contributing to HIV/AIDS and risky sexual behaviour among learners.

\begin{tabular}{|c|c|c|}
\hline Codes & Issue discussed & Themes identified \\
\hline $\begin{array}{l}\text { Knowledge and attitude towards } \\
\text { HIV/AIDS }\end{array}$ & $\begin{array}{l}\text { Signs of learners not taking HIV/AIDS seriously as disease } \\
\text { that kills }\end{array}$ & Ignorant \\
\hline Socio-economic status & $\begin{array}{l}\text { Does poverty plays a role in the spread of HIV/AIDS } \\
\text { among learners }\end{array}$ & Poverty \\
\hline Peer influence & Doing what other learners do. & Peer pressure \\
\hline Substance abuse & $\begin{array}{l}\text { Alcohol and drugs being used by learners in school } \\
\text { The effect of alcohol and drugs }\end{array}$ & $\begin{array}{l}\text { Alcohol and drug } \\
\text { abuse }\end{array}$ \\
\hline Knowledge of condom use & Rate of teenage pregnancy & Unprotected sex \\
\hline Multiple sex partners & Learners being paid for sex & Promiscuity \\
\hline
\end{tabular}

Table 3. From Basic Themes to Organising Themes and Global Themes

\begin{tabular}{|c|c|c|c|}
\hline No. & Basic Themes & Organising Themes & Global Themes \\
\hline \multirow{3}{*}{1.} & $\begin{array}{l}\text { Alcohol, Tobacco, Hubbly bubbly, Tavern, Entertainment, } \\
\text { school toilets, etc. }\end{array}$ & Substance abuse and setting & $\begin{array}{l}\text { Substance } \\
\text { abuse }\end{array}$ \\
\hline & $\begin{array}{l}\text { Sleeping in class, difficulty studying, absent from } \\
\text { school,performance drops, failure, repeat grade, drop out } \\
\text { ofschool }\end{array}$ & Effects of substance abuse & $\begin{array}{l}\text { Substance } \\
\text { abuse }\end{array}$ \\
\hline & $\begin{array}{l}\text { Entertainment, Friends, Accessibility and affordability, } \\
\text { Environmental factors. }\end{array}$ & $\begin{array}{l}\text { Reasons for alcohol and drug use } \\
\text { Experimenting } \\
\text { Peer pressure }\end{array}$ & $\begin{array}{l}\text { Substance } \\
\text { abuse }\end{array}$ \\
\hline 2. & $\begin{array}{l}\text { No source of income } \\
\text { Unemployed parents/family } \\
\text { Illiteracy among family members } \\
\text { Do not get things I need (Multiple sex partners) }\end{array}$ & Socio-economic status & Poverty \\
\hline 3. & $\begin{array}{l}\text { Condom use and distribution, teenage pregnancy, lack of } \\
\text { knowledge and information regarding HIV/AIDS, attitude } \\
\text { towards HIV/AIDS and ignorance. }\end{array}$ & Health and behaviour & $\begin{array}{l}\text { HIV/AIDS } \\
\text { Education }\end{array}$ \\
\hline
\end{tabular}




\section{Discussion}

\section{Global Theme 1: Substance Abuse}

Most of the participants agreed that there had been cases of alcohol or drug abuse in their school. Furthermore, they opined that drugs and alcohol can be a leading factor in the spread of HIV/AIDS as when someone is under the use of substances, they cannot control themselves.

One participant expressed these views:

"Other learners report their fellow learners who abuses alcohol and drugs, procedures taken by educators are that parents are called in at school to discuss the behaviour of the child/learner".

Participants reported that learners use alcohol and drugs for the following reasons: Experimenting and peer pressure.

\section{Sub-Theme Entertainment of Substances: Experimenting and Peer Pressure}

One participant reported that other learners report those who use substances in school premises, it may be because individuals want to know how other feel after using the substance, hence it is said that one is experimenting.

Most of the participants' responses was "yes", the environment does have an influence, it depends on the community the learner comes from, and the standard of living.

Two of the participants expressed their views on this matter, one of them said:

When a learner comes from a poor community, they may be influenced to start engaging in a relationship with someone who will be able to give them what they need.

The other participant said:

Learner who comes from a community where accessibility of substances are easily available, this will have a negative influence as the learners will have access to substances like alcohol and when they have consumed alcohol they will not be able to control themselves as this can lead to unprotected sexual engagement.

\section{Global Theme 2: Poverty}

Most of the participants indicated that family background does play a role in spread of HIV/AIDS among learners as some contract HIV/AIDS during birth, as some of the learners come from poor families and they do not have what they need, hence some of them engage is relationships with older persons who reward them with money to get what they need.

This participant made his own views on poverty among learners very clear:

"Learners are sleeping with older people to get money from them."

One of the participants said:

"When a learner comes from a poor community, the learner can be influenced to start engaging in a relationship with someone who will be able to give her what she needs".

\section{Global Theme 3: HIVIAIDS Education}

Most of the educators indicated that young people are ignorant and act irresponsibly because they are being taught about the dangers of HIV/AIDS and seem carefree. They want to believe that HIV/AIDS and STI's are real when one has already been infected. Life orientation educators educate learners about HIV/AIDS as it is a content on each Life orientation textbook.

One of the educators said:

"Young people are careless, there are condoms to use when engaging in sexual intercourse but they do not use them".

The rate of teenage pregnancy is one of the signs that shows that learners are engaging in unprotected sex and also not using condoms which makes them to be at risk of contract HIV/AIDS.

\section{Recommendations}

Recommendations for reducing risky behaviour among youths were made based on the conclusions drawn from the findings. These are outlined below.

1 The researcher recommends that the Department of Health should do regular sessions with adolescents at school; equip them with information regarding HIV/AIDS and other sexual transmitted diseases. 
2 The Department of Education should organise teenage pregnancy workshops in the schools; the workshops should address teenage pregnancy and the dangers of engaging in unprotected sex with regards to HIV/AIDS.

3 The government should establish poverty alleviation programmes which will be of benefit in assisting young people to be self-employed in order to decrease the high rate of teenage pregnancy.

4 Love life programmes should better their services and have ways of encouraging and making their groups interesting for learners to stay for their sessions and programmes after school hours.

5 There is a lack of recreational facilities in the school and also in the community; the government should create recreational facilities that will keep young people out of taverns and from abusing drugs.

\section{Conclusion}

In conclusion, this study found out that poverty, age, environment and substances are factors that contribute to risky sexual behaviour and HIV/AIDS among learners. This study confirms that female learners are more likely to experience sexual activities earlier than males thus exposing them to the risk of sexual transmitted infections such as HIV.

\section{Competing Interests Statement}

The authors declare that there are no competing or potential conflicts of interest regarding the publication of the paper.

\section{References}

Amuzu, J. (2007). HIV/AIDS: The challenges for young people.Commonwealth Youth and Development, 5(1).

Barnette, T., \& Whiteside, A. (2002). AIDS in the Twenty-First Century. New York: Palgrave Macmillan. https://doi.org/10.1057/9780230599208

Bouare, O. (2009). Modelling Contextual Determinants of HIV/AIDS Prevalence in South Africa to Inform Policy. African Journal of Reproductive Health, 13.

Cresswell, J. W. (2003). Research Design-Qualitative, quantitative and mixed methods approaches (2nd ed.). Thousands Oaks, CA: Sage.

Goddard, W., \& Melville, S. (2001).Research methodology (2nd ed.). Landsdowne: JUTA.

Klomegah, R. Y. (2011). Sexual behaviour and HIV/AIDS in Sub-Saharan Africa: A Comparative Analysis of Swaziland and Niger. International Review of Modern Sociology, 37(2).

Marais, H. (2005).Buckling: The impact of AIDS in South Africa 2005.Pretoria: University of Pretoria.

Molefe, K. M. (2013). Risky sexual behaviour among the Youth of South Africa.Mafikeng. NWU-Mafikeng Campus (Dissertation-MA).

Ndinga-Muvumba, A., \& Pharoah, R.(2008).HIV/AIDS and Society in South Africa. Kwa-Zulu-Natal: University of Kwa-Zulu-Natal Press.

Okorie, N., \& Bigala, P. (2016).Creating HIV/AIDS awareness through localised communication for health development in South Africa. Journal of Health Management, 18(3), 439-446. https://doi.org/10.1177/0972063416651567

Tarkang, E. E., van der Wal, D. M., \& Ehlers, V. J. (2011). The explanatory power of factors associated with the perceived risk of contracting HIV among senior secondary school learners In Kumba, Cameroon. Africa Journal of Nursing and Midwifery, 13(2).

UNAIDS (Joint United Nations Programme on HIV/AIDS). (1997). Women and AIDS'.UNAIDS Best Practice Collection. New York and Geneva: UNAIDS.

Zastrow, C. H., \& Kirst-Ashman, K. K. (2013). Understanding human behaviour and the social environment. United States, BROOKS/COLE: Cengage Learning.

\section{Copyrights}

Copyright for this article is retained by the author(s), with first publication rights granted to the journal.

This is an open-access article distributed under the terms and conditions of the Creative Commons Attribution license (http://creativecommons.org/licenses/by/4.0/). 